\title{
Analysis of bull (Bos taurus) seminal vesicle fluid proteome in relation to seminal plasma proteome
}

\author{
B. Westfalewicz, ${ }^{* 1}$ M. A. Dietrich, ${ }^{*}$ A. Mostek, ${ }^{*}$ A. Partyka,† W. Bielas, $†$ W. Niżański, $\dagger$ and A. Ciereszko* \\ *Department of Gamete and Embryo Biology, Institute of Animal Reproduction and Food Research, Polish Academy of Sciences, Tuwima 10, \\ 10-748 Olsztyn, Poland \\ †Department of Reproduction and Clinic of Farm Animals, Faculty of Veterinary Medicine, Wrocław University of Environmental and Life Sciences, \\ pl. Grunwaldzki 49, 50-366 Wrocław, Poland
}

\begin{abstract}
The existing knowledge on the bull seminal vesicle proteome, a major seminal plasma constituent, and its relationship with seminal plasma is limited. This knowledge is prerequisite for a better understanding of seminal plasma variability, which is linked to semen quality. The objective of this study was to characterize the proteomes of seminal vesicle fluid and seminal plasma and to compare them to better understand the origin of seminal plasma proteins. We collected ejaculates and seminal vesicle fluid postmortem from 6 mature Holstein Friesian bulls. We performed the analysis and identification of proteins using 2-dimensional electrophoresis coupled with matrix-assisted laser desorption/ionization mass spectrometry. We identified 105 proteins in bull seminal vesicle fluid and 88 proteins in seminal plasma. For both seminal vesicles and seminal plasma proteins described in our study, top biological functions were cellular movement, cell death and survival, and cellular growth and proliferation. Additionally, seminal vesicle fluid proteins were involved in protein degradation and synthesis. Seminal plasma proteins were also involved in cellular assembly and organization and cell-to-cell signaling and interactions. Proteins of both fluids were involved in the following canonical pathways: glycolysis, gluconeogenesis, liver X receptor/farnesoid X receptor, and farnesoid X receptor/retinoid X receptor activation. Additionally, seminal vesicle fluid proteins appeared to be involved in oxidative stress response mediated by nuclear factor E2-related factor 2. Our results described the bull seminal vesicle fluid proteome for the first time and allowed for significant expansion of the current knowledge on the bull seminal plasma proteome. Moreover, analysis indicated that both bull seminal vesicle fluid and semi-
\end{abstract}

Received August 12, 2016.

Accepted November 4, 2016.

${ }^{1}$ Corresponding author: b.westfalewicz@pan.olsztyn.pl nal plasma proteomes contained interconnected protein groups related to protective functions, glycolysis, and the morphology and physiology of the spermatozoa. These proteins and their interactions could be targeted in future research.

Key words: bull, proteome, seminal vesicle, seminal plasma

\section{INTRODUCTION}

Semen is a complex mixture consisting of spermatozoa and the liquid known as seminal plasma. The seminal plasma is created during ejaculation by combining epididymal fluid with secretions of accessory sexual glands. In bull, the 4 accessory sex glands consist of seminal vesicles, prostate, bulbourethral glands, and ampulla. Secretion from seminal vesicles makes up the majority of bull seminal plasma (Juyena and Stelletta, 2012). Seminal plasma mainly functions as a nourishment medium for spermatozoa that allows for their transportation, but also plays an important role in major physiological events such as capacitation and spermatozoa-oocyte interaction (Desnoyers and Manjunath, 1992). Seminal plasma constituents include ions, energy substrates (mainly fructose in case of bull sperm), organic compounds, peptides, and proteins. The protein constituent of seminal plasma is vital in efficient fertilization, as it influences spermatozoa plasma membrane stability, motility, capacitation, and spermegg interaction (Juyena and Stelletta, 2012).

Research into the bull proteome of seminal plasma and secretions of the reproductive tract has been initiated and allows the description and identification of numerous proteins. To our knowledge, 2 proteomic studies have been published to date concerning comprehensive proteome analysis of seminal plasma. Kelly et al. (2006) described 99 proteins in bull seminal plasma and provided the identification of multiple proteins that had not previously been reported there. Rego et al. (2014) provided a proteomic map of seminal plasma with 108 identified protein spots, corresponding to 46 proteins, 
and proposed putative seminal protein functions during sperm maturation, protection, capacitation, and fertilization. The results of those studies provided a solid foundation to better understand the functions of bull semen.

Despite significant advances in bull reproductive tract proteomic research, knowledge regarding the participation of particular protein components in seminal plasma from different accessory sex gland secretions is not well advanced. Such knowledge is especially important for the characterization of seminal vesicle fluid, because it is the main component of seminal plasma. To the best of our knowledge, only one study has been performed concerning the accessory sexual gland secretion proteome of the bull (Moura et al., 2007). Those authors collected accessory sexual gland secretions separated from sperm cells and epididymal fluid by the catheterization of duct deferens. Proteomic analysis allowed an average of 52 protein spots to be found on 2-dimensional (2-D) gels, which corresponded to 13 proteins. The identification and characterization of those proteins suggested their roles in sperm physiology after ejaculation. Whereas those results shed some light on seminal plasma protein component origins and accessory sex gland functions, they could not, by design, differentiate between particular gland proteomes. In particular, the seminal vesicle fluid proteome was not established; for this reason, its relation with seminal plasma is still not fully understood. Moreover, insight into seminal plasma composition dependence on seminal vesicles and other accessory sex gland fluids could help to explain the variability of seminal plasma. It is especially worth investigating, as recent results on ram seminal plasma show that seminal plasma variability can affect the success of certain biotechniques, such as cryopreservation (Rickard et al., 2016). Recently, seminal plasma proteins bound to spermatozoa membranes, such as binder of sperm protein or calmodulin, have been found to be present in different abundance in X- or Y-bearing bull spermatozoa obtained via flow cytometry (De Canio et al., 2014). This suggests that seminal proteome can influence the outcome of flow cytometry. This idea is supported by the work of de Graaf et al. (2008), who suggested that seminal plasma influence on ram spermatozoa membranes might reflect on sex-sorted spermatozoa. Identifying the seminal vesicle proteome and its relation to seminal plasma proteome might allow for greater insight into efficiency of sperm sorting and storage of sex-sorted spermatozoa, as well as mechanisms differentiating between $\mathrm{X}$ and $\mathrm{Y}$ spermatozoa characteristics.

In this study, we aimed to compare seminal plasma and seminal vesicle fluid proteomes to better under- stand the relationship between those 2 fluids. We collected ejaculates and postmortem seminal vesicle fluid from 6 mature Holstein Friesian bulls. Our study led to the identification of 105 proteins from seminal vesicle fluid and 85 proteins from seminal plasma. Additionally, we performed comprehensive functional analysis of the highest number (128) of bull seminal plasma proteins to date by using our data combined with those of Kelly et al. (2006) and Rego et al. (2014).

\section{MATERIALS AND METHODS}

\section{Sample Collection and Initial Semen Analysis}

All samples were collected from 6 mature Holstein Friesian bulls provided by the Breeding and Insemination Station in Karczew. Semen was collected using an artificial vagina during routine work of the Station. Seminal vesicle fluid was collected from 6 bulls, postmortem, by the Department of Reproduction and Clinic of Farm Animals (Wrocław, Poland). Initial semen quality assessment was performed on site by the Breeding and Insemination Station according to standard commercial procedures.

\section{Semen Analysis Using Flow Cytometry}

In addition to initial analysis, semen quality was assessed with the use of flow cytometry in the Department of Reproduction and Clinic of Farm Animals. Sperm membrane integrity was determined by the double-fluorescent labeling technique, using a Live/Dead Sperm Viability Kit (Life Technologies Ltd., Grand Island, NY). Briefly, $300 \mu \mathrm{L}$ of the diluted samples was stained with $5 \mu \mathrm{L}$ of SYBR-14 (commercial solution diluted 50 -fold) and $5 \mu \mathrm{L}$ of propidium iodide (PI). The PI negative and SYBR-14 positive population showing green fluorescence was considered live, with the sperm plasma membrane intact. Sperm acrosome status was assessed using lectin peanut agglutinin from Arachis hypogaea Alexa Fluor 488 conjugate (Thermo Fisher Scientific, Waltham, MA). Diluted semen samples were mixed with $10 \mu \mathrm{L}$ of lectin peanut agglutinin working solution $(1 \mu \mathrm{g} / \mathrm{mL})$ and incubated for $5 \mathrm{~min}$ at room temperature in the dark. After incubation, the samples were washed and $5 \mu \mathrm{L}$ of PI was added before cytometric analysis. Flow cytometric analyses were performed on a FACSCalibur (Becton Dickinson, San Jose, CA) cytometer. The fluorescent probes used in the experiment were excited by an Argon ion $488 \mathrm{~nm}$ laser. Acquisitions were performed using the CellQuest 3.3 software (Becton Dickinson). The non-sperm events were gated out based on scatter properties and were 
not analyzed. In total, 40,000 events were analyzed for each sample.

\section{Sample Preparation for 2-D SDS-PAGE}

Seminal plasma was processed immediately after acquisition of the ejaculate. An aliquot of $0.5 \mathrm{~mL}$ of fresh semen was centrifuged at $900 \times g$ for $30 \mathrm{~min}$ at $4^{\circ} \mathrm{C}$ to separate seminal plasma from spermatozoa. Seminal plasma was then transported at $4^{\circ} \mathrm{C}$ and frozen at $-80^{\circ} \mathrm{C}$ until further use. Vesicular glands were preparated immediately postmortem and their contents were manually expelled directly into the Eppendorf tubes and frozen at $-80^{\circ} \mathrm{C}$ until further use. After thawing, both seminal plasma and seminal vesicle fluid samples were centrifuged at $10,000 \times g$ at $4^{\circ} \mathrm{C}$ for $60 \mathrm{~min}$ to remove any remaining debris from the liquid. After centrifugation, aliquots containing approximately 700 $\mu \mathrm{g}$ of protein were cleaned with a Clean-Up Kit (GE Healthcare, Uppsala, Sweden) according to the manufacturer's protocol. The protein concentration before and after the cleaning procedure was measured by the Coomassie (Bradford) Protein Assay Kit (Thermo Fisher Scientific). No protease inhibitors were used during sample preparation, according to protocols previously used during bull seminal plasma (Kelly et al., 2006; Rego et al., 2014) and accessory gland fluid (Moura et al., 2007) preparation.

\section{2-D SDS-PAGE}

Samples containing $500 \mu \mathrm{g}$ of protein were resuspended in rehydration buffer ( $7 M$ urea, $2 M$ thiourea, $2 \% 3$-[(3-cholamidopropyl)-dimethylammonio]-1-propanesulfonate, $2 \%$ immobilized $\mathrm{pH}$ gradient buffer, 40 $\mathrm{m} M$ dithiothreitol, $0.002 \%$ bromophenol blue) to reach a final volume of $450 \mu \mathrm{L}$. Samples were then loaded on $24 \mathrm{~cm}$ Immobiline DryStrips, 3-10 NL pH range (GE Healthcare), and rehydrated for $10 \mathrm{~h}$. Proteins were then separated by isoelectric focusing on an Ettan IPGphor apparatus (GE Healthcare) operating at $20^{\circ} \mathrm{C}$ with current limited to $50 \mu \mathrm{A}$ per strip and the following voltage program: $500 \mathrm{~V} / 5 \mathrm{~h}, 1,000 \mathrm{~V} / 1 \mathrm{~h}, 8,000$ $\mathrm{V} / 3 \mathrm{~h}$, and $8,000 \mathrm{~V} / 5.5 \mathrm{~h}$. After isoelectric focusing, the strips were equilibrated in SDS equilibration buffer (6 $M$ urea, $75 \mathrm{~m} M$ Tris- $\mathrm{HCl}$, pH 8.8, 29.3\% glycerol, $2 \%$ SDS, and a trace of bromophenol blue) containing $10 \mathrm{mg} / \mathrm{mL}$ of dithiothreitol for $15 \mathrm{~min}$ and then in SDS equilibration buffer containing $25 \mathrm{mg} / \mathrm{mL}$ of iodoacetamide for $15 \mathrm{~min}$. The equilibrated strips were then transferred to manually cast $12.5 \%$ gels $(25.5 \times$ $19.6 \mathrm{~cm}, 1 \mathrm{~mm}$ thickness) and sealed with $0.5 \%$ agarose. A second dimension of electrophoresis was then performed at $1 \mathrm{~W}$ /gel in an Ettan Dalt-Six apparatus (GE Healthcare) for $16 \mathrm{~h}$.

\section{Image Acquisition and Analysis}

After electrophoresis, the gels were stained using Coomassie Brilliant Blue and scanned with an ImageScanner III (GE Healthcare). Acquired images were analyzed using Image Master 2D Platinum 7.0 (GE Healthcare). The software was used to automatically detect the protein spots, and spots consistently occurring in images from every individual were selected for identification. Selected spots were indicated for selection in a spot pick list created by the software.

\section{Excision and Spot Identification Using Matrix- Assisted Laser Desorption/lonization Time-of-Flight Tandem Mass Spectrometry}

Spots were automatically picked from gels with an Ettan Spot Picker (GE Healthcare), which picked the spots on the basis of a spot pick list generated by Image Master Platinum. Picked spots were put in a 96-well collection plate, and transferred to Ettan Digester (GE Healthcare). Spots were then digested using the following protocol: (1) 3 consecutive washes with $200 \mu \mathrm{L}$ of $50 \%$ methanol, $20 \mathrm{mM} \mathrm{NH} \mathrm{NCO}_{3}, 25 \mathrm{~min}$ each, (2) 2 consecutive washes with $200 \mu \mathrm{L}$ of $100 \%$ acetonitrile, $5 \mathrm{~min}$ each, (3) $100 \mu \mathrm{L}$ wash with $100 \%$ acetonitrile, left to dry for over $15 \mathrm{~min}$, and (4) the addition of $10 \mu \mathrm{L}$ of $0.2 \mu \mathrm{g} / \mu \mathrm{L}$ modified sequencing grade trypsin (Promega, Madison, WI) solution in 50 $\mathrm{m} M \mathrm{NH}_{4} \mathrm{HCO}_{3}$ followed by incubation for $12 \mathrm{~h}$ at $37^{\circ} \mathrm{C}$. Peptide mixtures with gel spots were then sonicated briefly with a VCX-130 Ultrasonic Processor (Sonics \& Materials Inc., Newtown, CT), put in a Speedvac Concentrator (Thermo Fisher Scientific), and dried in a vacuum. The dried-out gel spots were discarded. Dried-out samples were then placed in an Ettan Spotter robot (GE Healthcare), where they were dissolved in matrix solution (5 $\mathrm{mg}$ of $\alpha$-cyano-4-hydroxycinnamic acid (Bruker Daltonics, Billerica, MA) in $1 \mathrm{~mL}$ of $50 \%$ acetonitrile in $0.1 \%$ trifluoroacetic acid) and spotted onto the MALDI target plate (MT 34 Target Plate Ground Steel, Bruker Daltonics) using the method "Dissolve Sample in Matrix First - Then Spot" with the following parameters: matrix volume: $3 \mu \mathrm{L}$, mix cycles number: 5 , mix volume: $3 \mu \mathrm{L}$, spot volume: 0.9 $\mu \mathrm{L}$, and airgap: $3 \mu \mathrm{L}$. After spotting, samples were left to dry. The matrix-assisted laser desorption/ionization time-of-flight (MALDI-TOF)/TOF MS analysis was carried out using a MALDI-TOF tandem mass spectrometer (Autoflex Speed, Bruker Daltonics). Collected 
Table 1. Bull semen parameters

\begin{tabular}{|c|c|c|c|c|c|c|}
\hline $\begin{array}{l}\text { Bull } \\
\text { no. }\end{array}$ & $\begin{array}{c}\text { Ejaculate } \\
\text { volume, } \mathrm{mL}\end{array}$ & $\begin{array}{c}\text { Spermatozoa } \\
\text { concentration, } \\
10^{9} \text { spermatozoa } / \mathrm{mL}\end{array}$ & $\begin{array}{l}\text { Quality of } \\
\text { movement }\end{array}$ & $\begin{array}{l}\text { Motility, } \\
\%\end{array}$ & $\begin{array}{c}\text { Live spermatozoa, } \\
\%\end{array}$ & $\begin{array}{c}\text { Spermatozoa } \\
\text { with intact } \\
\text { acrosome, \% }\end{array}$ \\
\hline 1 & 15.0 & 1.450 & $2 / 3$ & $>70$ & 58.7 & 58.9 \\
\hline 3 & 5.0 & 1.050 & $2 / 3$ & $>70$ & 75.8 & 77.7 \\
\hline 4 & 4.5 & 1.043 & $2 / 3$ & $>70$ & 84.2 & 67.9 \\
\hline 5 & 3.5 & 0.864 & $2 / 3$ & $>70$ & 89.8 & 81.3 \\
\hline
\end{tabular}

MS and MS/MS LIFT spectra of selected ions were externally calibrated using monoisotopic $[\mathrm{MpH}] \mathrm{p}$ ion peptide calibration standards (Bruker Daltonics) and imported to BioTools (Bruker Daltonics). The data were searched using a Mascot Server (Matrix Science, London, UK) in the National Center for Biotechnology Information database, with the following parameters: fixed modifications-carbamidomethyl (C); variable modifications-oxidation $(\mathrm{M})$; cleavage enzyme-trypsin; max missed cleavages-2, peptide mass tolerance-100 ppm, and fragment mass tolerance-0.6 kDa (Perkins et al., 1999).

\section{Ontology, STRING, and Ingenuity Pathway Analyses of the Identified Proteins}

Gene Ontology Annotation (GO) was acquired by matching the GI numbers of identified proteins to the UniProtKB database (www.uniprot.org; Huntley et al., 2015). The categories used were "molecular functions" and "biological process." Search Tool for the Retrieval of Interacting Genes/Proteins (STRING) neighborhood analysis was performed by searching the STRING database to detect possible functional associations (http:// string-db.org; Szklarczyk et al., 2015). The STRING analysis was performed on the seminal vesicle fluid proteome, as well as on seminal plasma proteins identified by our work, supplemented with data from Kelly et al. (2006) and Rego et al. (2014). On the produced protein networks, we selected groups of proteins based on following criteria: protein groups had to contain at least one protein connected to at least 4 other proteins with the highest confidence bonds (confidence of 0.900 , established by STRING software). Ingenuity Pathway analysis (IPA; Qiagen Silicon Valley, Redwood City, $\mathrm{CA}$ ) of the identified proteins used the Core Analysis function to interpret the identified proteins in the context of biological functions and pathways. The IPA was performed on proteins of seminal plasma, seminal vesicles, and seminal plasma proteins identified by our work, supplemented with data from Kelly et al. (2006) and Rego et al. (2014). The significance of biological functions and canonical pathways was tested auto- matically by the software, with use of the Fisher exact test $P$-value. Top significant functions and canonical pathways were selected by the software for each tested proteome.

\section{RESULTS}

\section{Bull Semen Parameters}

All bulls were fertile, as ensured by the Breeding and Insemination Station. Flow cytometry indicated that average of $77.62( \pm 12.95 \%)$ of spermatozoa cells were alive and had intact membranes, and $70.25 \%( \pm 10.13 \%)$ had intact acrosomes. Semen parameters provided by Breeding and Insemination Station and specific flow cytometry results are presented in Table 1.

\section{Characteristic of Bull Seminal Vesicle Fluid Proteome}

Analysis of 2-D SDS-PAGE gels of bull seminal vesicles fluid allowed the detection of an average of $450 \pm 33$ spots (Figure 1). Out of the spots detected on all 3 gels, 227 were identified, corresponding to 105 different proteins (Supplemental Table S1, https://doi. org/10.3168/jds.2016-11866). Ten proteins were over the total spot volume of $1 \%$ (Figure 1), and therefore recognized as major seminal vesicle fluid proteins (Figure 2A). Binder of sperm protein 1 (BSP1), represented by 4 spots, accounted for the highest percentage of total spot volume detected in gels, followed by spermadhesins (SPHZ1 and SPHZ13) represented by 15 spots, serum albumin precursor (ALB) represented by 17 spots, seminal ribonuclease (SRN) represented by 3 spots, binder of sperm protein 5 (BSP5) represented by 10 spots, metalloproteinase inhibitor 2 (TIMP2) represented by 5 spots, clusterin (CLU) represented by 5 spots, seminal fluid protein A3 (SFPA3) represented by 3 spots, and plasma serine protease inhibitor precursor (SERPINA5) represented by 10 spots. Together, all of the above protein spots accounted for $63.69 \%$ of total spot volume detected in gel. 


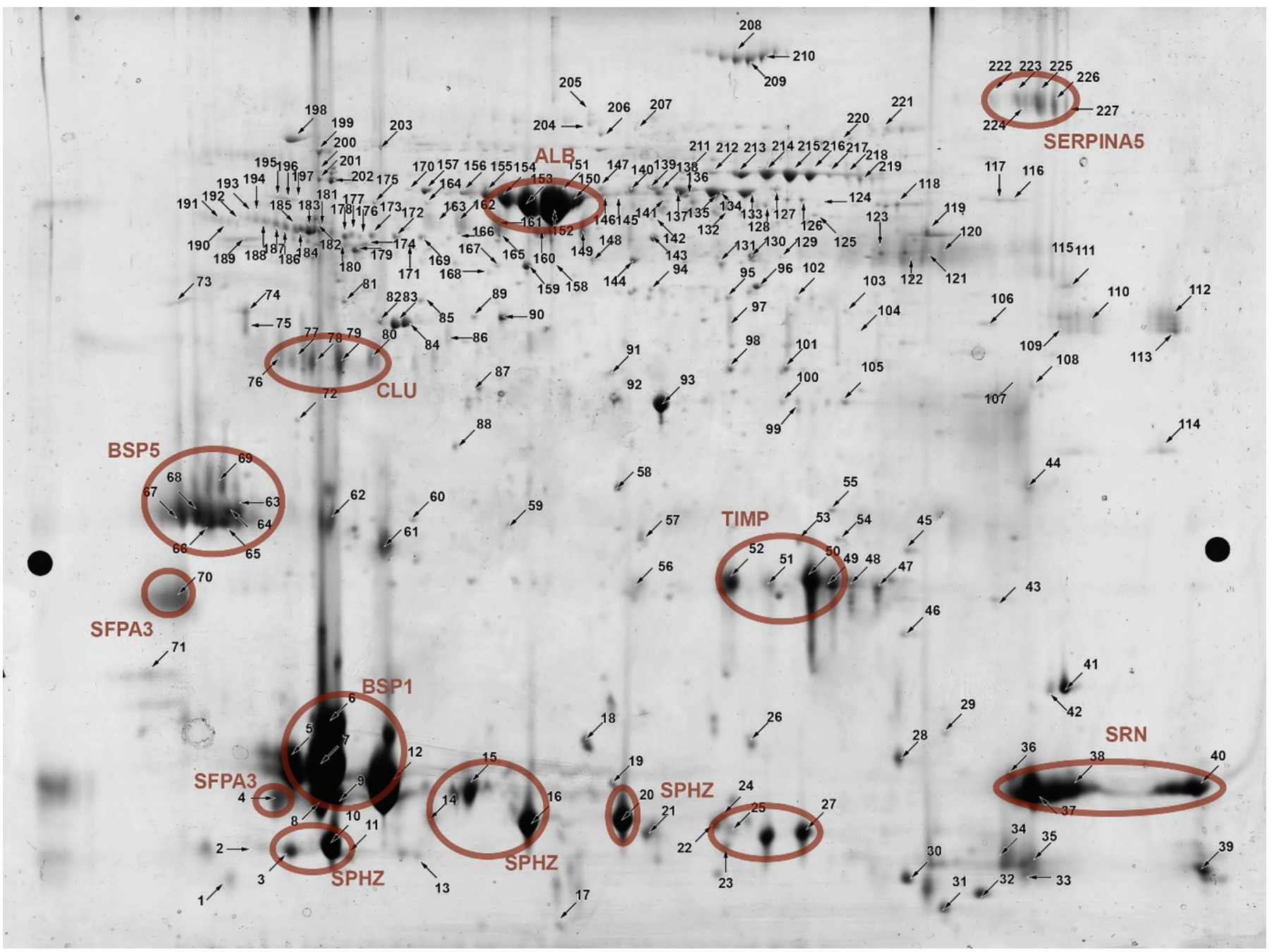

Figure 1. Two-dimensional SDS-PAGE gel of bull seminal vesicles fluid; arrows correspond to spot numbers presented in Supplemental Table S1 (https://doi.org/10.3168/jds.2016-11866). Ovals indicate proteins where the total spot volume detected in gels was greater than 1\%. ALB = serum albumin precursor; BSP1 = binder of sperm protein 1 ; BSP5 $=$ binder of sperm protein 5 ; CLU = clusterin; SERPINA5 = plasma serine protease inhibitor precursor; SRN = seminal ribonuclease; SFPA3 = seminal fluid protein A3; SPHZ = spermadhesin; TIMP = metalloproteinase inhibitor, chain T. Color version available online.

Functional analysis of the identified seminal vesicle fluid proteins by IPA allowed for the detection of functions and canonical pathways associated with proteins. The top functions indicated by IPA were cellular movement, cell death and survival, cellular growth and proliferation, protein degradation, and protein synthesis (Table 2). The top canonical pathways were liver $\mathrm{X}$ receptor/farnesoid X receptor (LXR/FXR) activation, glycolysis I, farnesoid X receptor/retinoid X receptor (FXR/RXR) activation, NRF2-mediated oxidative stress response, and gluconeogenesis I (Table 3). Full information on functions and canonical pathways is presented in Supplemental Tables S2 and S3 (https:// doi.org/10.3168/jds.2016-11866).
Identified seminal vesicles fluid proteins were also subjected to GO analysis (Figure $2 \mathrm{~B}$ and $2 \mathrm{C}$ ). Out of 105 proteins, 100 were successfully categorized according to molecular function and biological process. Based on molecular function analysis, proteins were divided into 7 groups, with the majority having binding, catalytic, and molecular function regulator activity. Based on biological process analysis, proteins were divided into 12 groups, with the majority being involved in metabolic processes, cellular processes, and biological regulation.

The identified proteins were also subjected to STRING neighborhood analysis (Figure 3). Out of 105 proteins, 91 were successfully recognized in the 


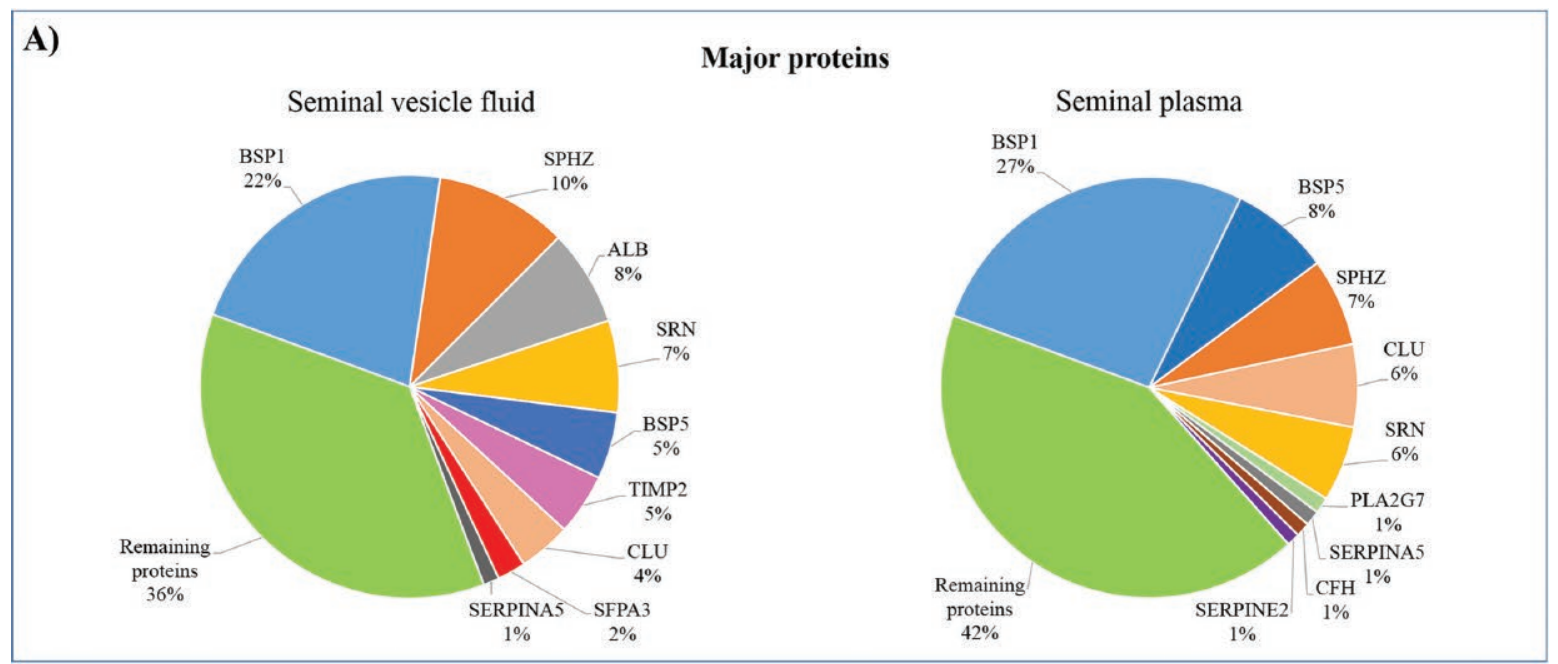

B)

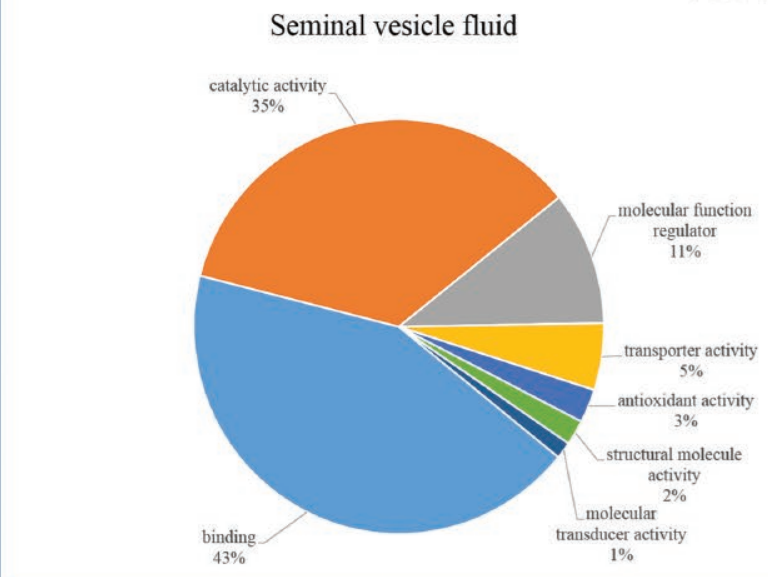

Seminal plasma

C)

Seminal vesicle fluid

Biological process
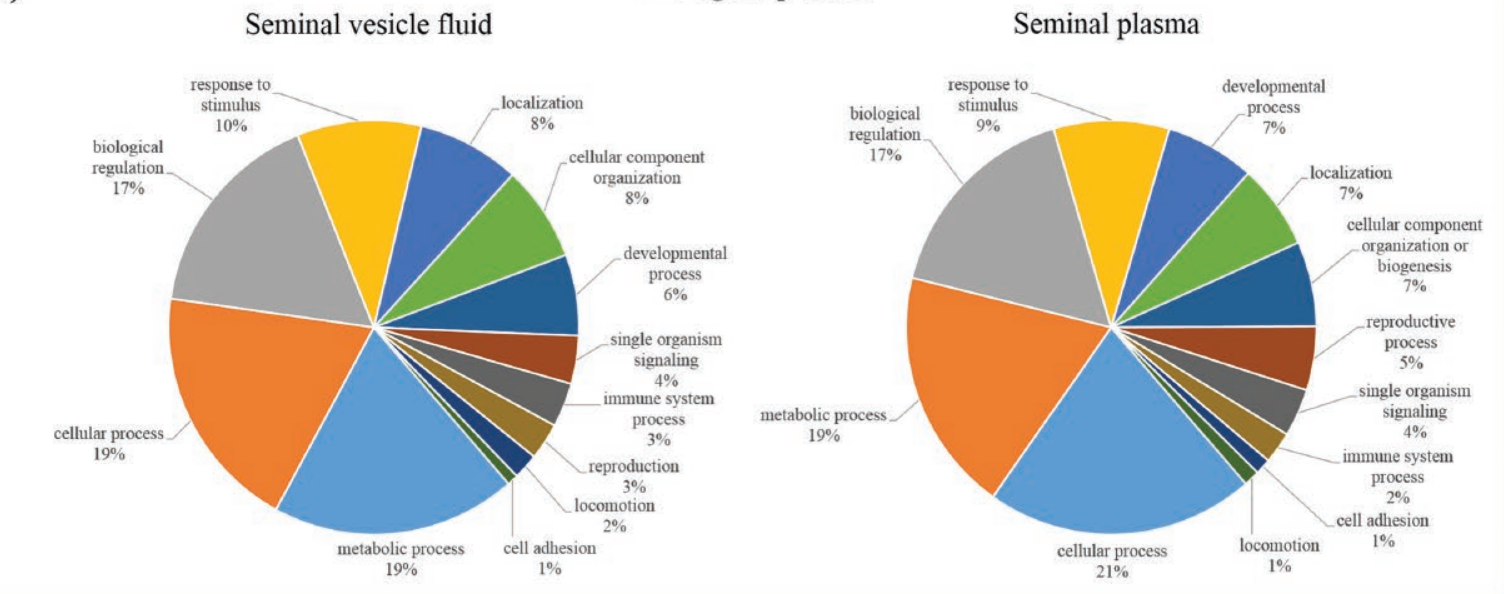

Figure 2. Pie charts presenting the major proteins of bull seminal vesicle fluid and seminal plasma (A), as indicated by the analysis of electropherograms presented in Figures 1 and 4, respectively, and ontological analysis of identified proteins from bull seminal vesicle fluid and seminal plasma. Classification of the protein set was performed according to the Gene Ontology terms molecular function (B) and biological process (C). BSP1 = binder of sperm protein 1; SPHZ = spermadhesin; ALB = serum albumin precursor; SRN = seminal ribonuclease; BSP5 = binder of sperm protein 5 ; TIMP2 = metalloproteinase inhibitor 2 ; CLU = clusterin; SFPA3 = seminal fluid protein A3; SERPINA5 = plasma serine protease inhibitor precursor; PLA2G7 = phospholipase A2 group VII; CFH = complement factor H precursor; SERPINE2 = serpin peptidase inhibitor. Color version available online. 
Table 2. Top biological functions performed by proteins identified in bull seminal vesicle and seminal plasma

\begin{tabular}{lcc}
\hline Function name & $P$-value range & Number of molecules \\
\hline Seminal vesicle fluid & & \\
Cellular movement & $2.10 \mathrm{E}-03$ to $3.27 \mathrm{E}-15$ & 40 \\
Cell death and survival & $1.96 \mathrm{E}-03$ to $7.22 \mathrm{E}-12$ & 44 \\
Cellular growth and proliferation & $1.34 \mathrm{E}-03$ to $1.83 \mathrm{E}-10$ & 18 \\
Protein degradation & $1.87 \mathrm{E}-03$ to $11.4 \mathrm{E}-09$ & 24 \\
Protein synthesis & $1.87 \mathrm{E}-03$ to $11.4 \mathrm{E}-09$ & \\
Seminal plasma & & 48 \\
Cell death and survival & $2.81 \mathrm{E}-03$ to $1.24 \mathrm{E}-12$ & 27 \\
Cellular assembly and organization & $2.55 \mathrm{E}-03$ to $4.02 \mathrm{E}-11$ & 28 \\
Cell-to-cell signaling and interaction & $2.34 \mathrm{E}-03$ to $1.73 \mathrm{E}-10$ & 32 \\
Cellular movement & $2.74 \mathrm{E}-03$ to $8.04 \mathrm{E}-10$ & 32 \\
Cellular growth and proliferation & $2.58 \mathrm{E}-03$ to $1.84 \mathrm{E}-09$ & \\
\hline
\end{tabular}

STRING database and represented as a network of proteins connected with confidence-based edges. Three groups of proteins were selected: one consisted of 17 proteins, whereas the other 2 consisted of 6 proteins.

\section{Characteristic of Bull Seminal Plasma Proteome}

Analysis of 2-D SDS-PAGE gels of bull seminal plasma proteins allowed for the detection of an average of $332 \pm 24$ spots (Figure 4). Overall, 199 spots were detected on all 3 gels, corresponding to 85 different proteins (Supplemental Table S4, https://doi.org/10.3168/ jds.2016-11866). Ten proteins were over the total spot volume of $1 \%$ (Figure 4), and therefore recognized as major seminal plasma proteins (Figure 2A). Binder of sperm protein 1, represented by 9 spots, accounted for the highest percentage of total spot volume detected in gels, followed by BSP 5 represented by 9 spots, isoforms of SPHZ1 and SPHZ13 represented by 10 spots, CLU represented by 15 spots, SRN represented by 4 spots, phospholipase A2 group VII (PLA2G7) represented by 7 spots, SERPINA5 represented by 5 spots, complement factor $\mathrm{H}$ precursor $(\mathrm{CFH})$ represented by 7 spots, and serpin peptidase inhibitor (SERPINE2) represented by 2 spots. Together, all of those protein spots accounted for $57.82 \%$ of the total spot volume detected in gels.

Functional analysis of identified seminal plasma proteins by IPA allowed for the detection of functions and canonical pathways associated with proteins. The top functions indicated by IPA were cell death and survival, cellular assembly and organization, cell-to-cell signaling and interaction, cellular movement, cellular growth, and proliferation (Table 2). The top canonical pathways were glycolysis I, gluconeogenesis I, LXR/ RXR activation, and FXR/RXR activation (Table 3). Full information on functions and canonical pathways is presented in Supplemental Tables S5 and S6 (https:// doi.org/10.3168/jds.2016-11866).

Identified seminal plasma proteins were also subjected to GO analysis (Figure $2 \mathrm{~B}$ and $2 \mathrm{C}$ ). Out of 85 proteins, 81 were successfully categorized according to the "molecular function" and "biological process." Based on "molecular function" analysis, proteins were divided into 7 groups, with the majority having binding, catalytic, and enzyme regulator activity. Based on "biological process" analysis, proteins were divided into

Table 3. Top canonical pathways associated with proteins identified in bull seminal vesicle fluid and seminal plasma $^{1}$

\begin{tabular}{lcc}
\hline Pathway name & $P$-value & Protein overlap, $\%$ \\
\hline Seminal vesicle fluid & & \\
LXR/RXR activation & $1.40 \mathrm{E}-09$ & $7.0(9 / 128)$ \\
Glycolysis I & $1.02 \mathrm{E}-08$ & $14.6(6 / 41)$ \\
FXR/RXR activation & $5.50 \mathrm{E}-08$ & $5.8(8 / 138)$ \\
NRF2-mediated oxidative stress response & $4.25 \mathrm{E}-07$ & $4.4(8 / 180)$ \\
Gluconeogenesis I & $8.52 \mathrm{E}-07$ & $10.9(5 / 46)$ \\
Seminal plasma & & $16.6(6 / 41)$ \\
Glycolysis I & $5.48 \mathrm{E}-09$ & $13.0(6 / 46)$ \\
Gluconeogenesis I & $1.13 \mathrm{E}-08$ & $3.2(4 / 125)$ \\
LXR/RXR activation & $9.09 \mathrm{E}-04$ & $3.1(4 / 138)$ \\
FXR/RXR activation & $1.31 \mathrm{E}-03$ & \\
\hline
\end{tabular}

${ }^{1} \mathrm{LXR} / \mathrm{RXR}=$ liver $\mathrm{X}$ receptor/retinoid $\mathrm{X}$ receptor; $\mathrm{FXR} / \mathrm{RXR}=$ farnesoid $\mathrm{X}$ receptor/retinoid $\mathrm{X}$ receptor activation. 


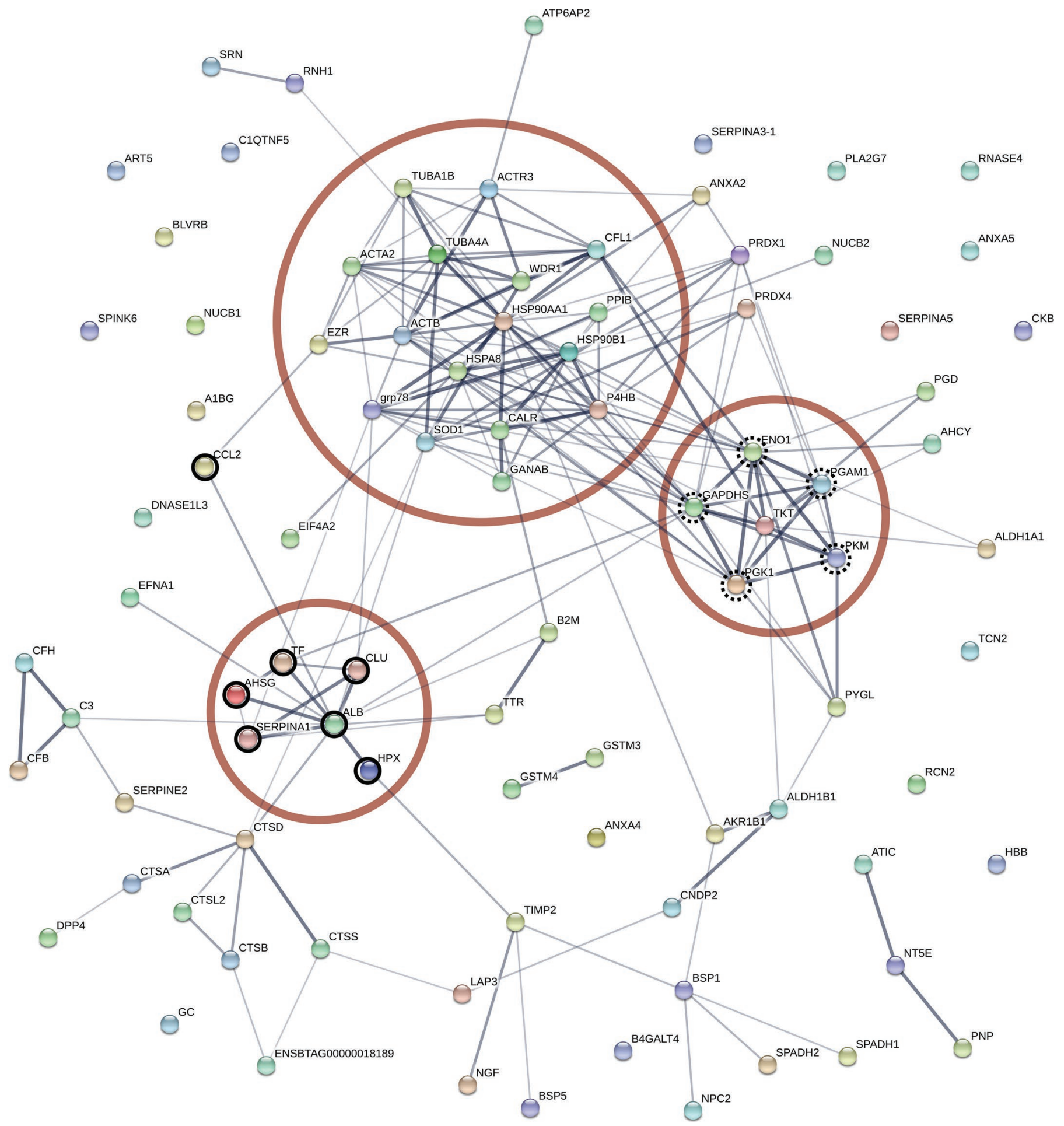

Figure 3. Search Tool for the Retrieval of Interacting Genes/Proteins (STRING) analysis of identified bull seminal vesicle fluid proteins; the proteins are connected with confidence network edges: the thicker the line, the greater the confidence of connection; protein groups containing at least one protein connected to at least 4 other proteins with highest confidence bonds are circled; black lines mark proteins involved in liver $\mathrm{X}$ receptor/farnesoid X receptor (LXR/FXR) and farnesoid X receptor/retinoid X receptor activation (FXR/RXR) activation pathways; dotted black lines mark proteins involved in glycolysis and gluconeogenesis. Full protein names can be found in the UniProtKB database (www.uniprot. org). Color version available online. 
12 groups, with the majority being involved in cellular processes, metabolic processes, and biological regulation.

\section{Comparison of Bull Seminal Plasma and Seminal Vesicles Fluid Electrophoretic Proteins Profile}

Comparison of the 2 fluids using 2-D SDS-PAGE gel revealed that 40 proteins were common for seminal plasma and seminal vesicle fluid. Full comparison between both fluids is presented in the form of a Venn diagram in Figure 5A; the list of proteins identified in seminal vesicle fluid only, seminal plasma only, and in both fluids is presented in Tables 4, 5, and 6. Many proteins were present in numerous proteoforms that varied between the fluids (Supplemental Tables S1 and S4; https://doi.org/10.3168/jds.2016-11866). Such protein proteoforms were identified with identical sequences determined by mass spectrometry. For example, albumin in seminal plasma was observed in 5 spots, but in seminal vesicle fluid it was in 17 spots.

\section{DISCUSSION}

To the best of our knowledge, in this study we have described the bull seminal vesicle fluid proteome for the first time. Previously, Moura et al. (2007) described the bull accessory sex gland fluid proteome, identifying 13 proteins. When compared with our identification of the seminal vesicle fluid proteome, we were able to confirm

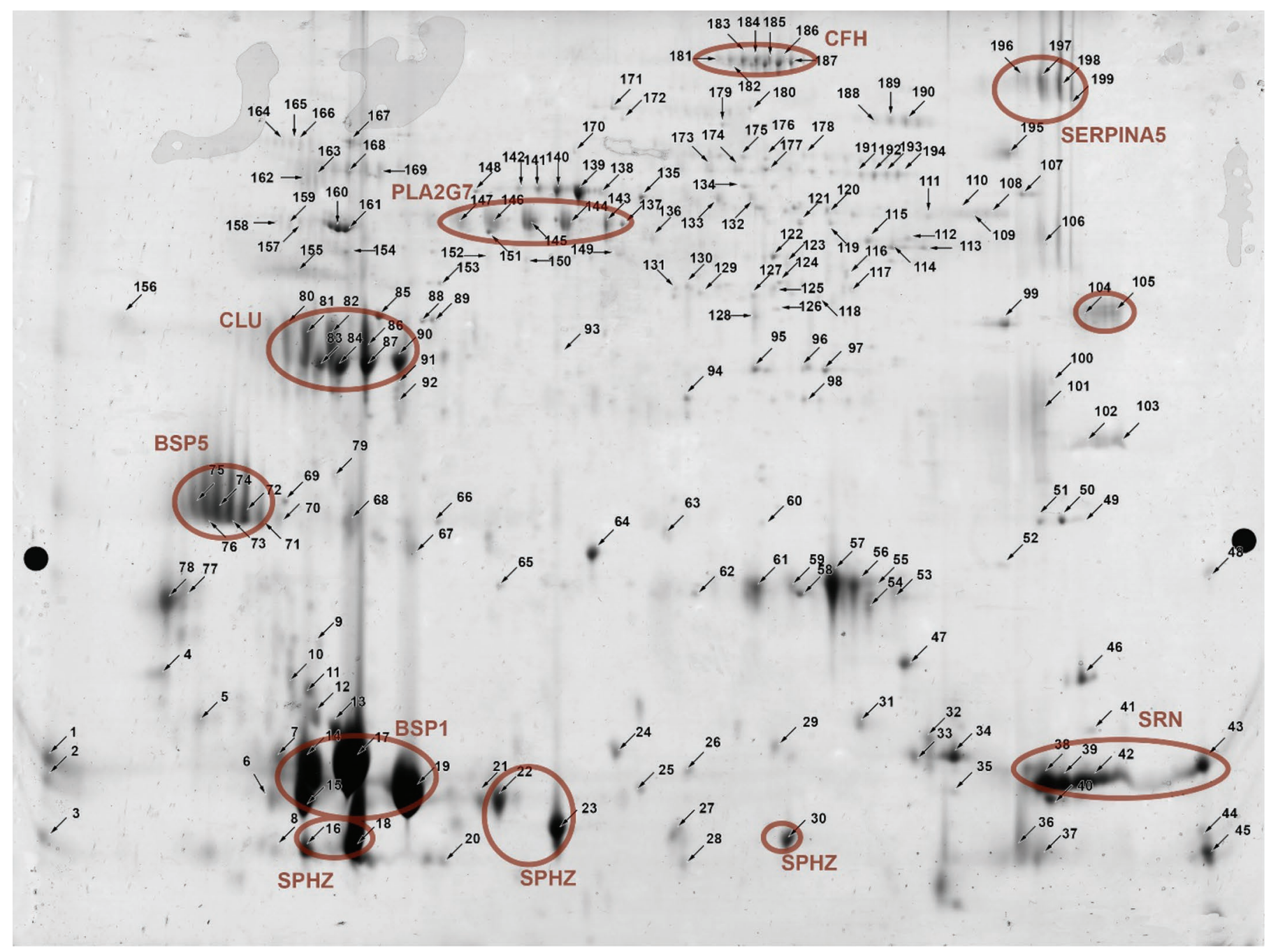

Figure 4. Two-dimensional SDS-PAGE gel of bull seminal plasma; arrows correspond to spot numbers presented in Supplemental Table S4 (https://doi.org/10.3168/jds.2016-11866). Ovals indicate proteins where the total spot volume detected in gels was greater than 1\%. BSP5 $=$ binder of sperm protein 5; CFH $=$ complement factor $\mathrm{H}$ precursor; CLU = clusterin; PLA2G7 = phospholipase A2 group VII; SERPINA5 $=$ plasma serine protease inhibitor precursor; SRN = seminal ribonuclease; SPHZ = spermadhesin; BSP1 = binder of sperm protein 1 . Color version available online. 
A)

\section{Bull seminal vesicle Bull seminal plasma fluid proteins proteins}

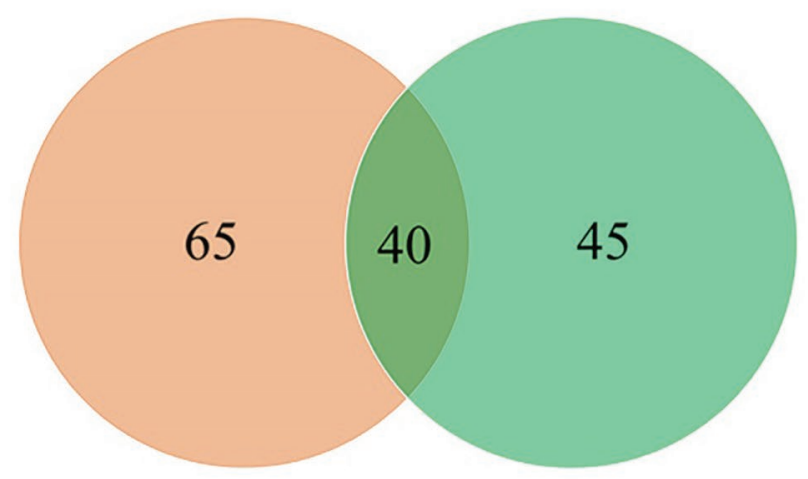

B)

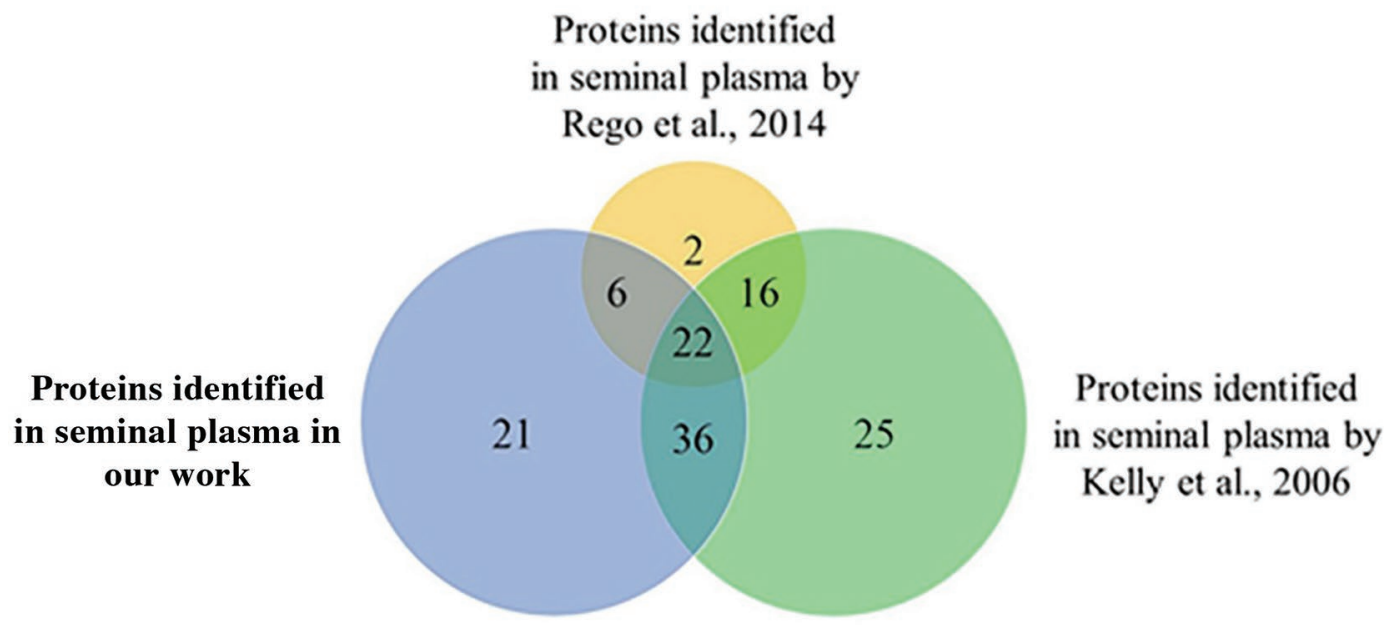

Figure 5. Venn diagrams comparing (A) the number of proteins identified in bull seminal vesicle proteins with proteins identified in bull seminal plasma in our work; overlapping area shows proteins found in both fluids, and (B) the number of bull seminal plasma proteins identified by our work, Rego et al. (2014), and Kelly et al. (2006). Color version available online.

the identity of 12 out of 13 proteins. Therefore, our results suggest that those 12 proteins identified in both works may originate from seminal vesicles. Osteopontin was the only protein found by Moura et al. (2007) in the mixture of accessory sex gland fluids but not in seminal vesicle fluids by our work. When we inspected images of seminal plasma and seminal vesicle fluid, we found very clear spots of osteopontin in seminal plasma, but not in seminal vesicle fluid, as shown in Supplemental Figure S1 (https://doi.org/10.3168/jds.2016-11866). Cancel et al. (1999) used Western blotting to demonstrate the presence of osteopontin in both seminal vesicles and ampulla fluids, which is contrary to our results. As in- dicated above, our results suggest that seminal vesicles cannot be the major source of osteopontin in seminal plasma. Therefore, it can be suggested that the bulk of osteopontin originates mostly from the ampulla glands. If results of further studies on osteopontin origin confirm our suggestion, osteopontin would be suggested as a marker of ampulla gland fluid in bull seminal plasma.

We were able to distinguish 3 groups of interconnected proteins in the bull seminal vesicle fluid proteome (Figure 3). The largest group contained multiple proteins with protective capabilities, molecular chaperones such as heat shock proteins (HSPA8, HSP90AA1, and HSP90B1) and the antioxidant enzyme (superoxide 
Table 4. Proteins found only in bull seminal vesicle fluid

\begin{tabular}{|c|c|}
\hline Protein name & Short name \\
\hline 6-Phosphogluconate dehydrogenase, decarboxylating & PGD \\
\hline $78 \mathrm{kDa}$ glucose-regulated protein precursor & HSPA5 \\
\hline Actin, aortic smooth muscle & ACTA2 \\
\hline Actin-related protein 3 & ACTR3 \\
\hline Aldehyde dehydrogenase, mitochondrial precursor & ALDH1B1 \\
\hline$\alpha-1$-Antiproteinase precursor & SERPINA1 \\
\hline$\alpha$-1B-Glycoprotein precursor & A1BG \\
\hline$\alpha-2$-HS-Glycoprotein precursor & AHSG \\
\hline Annexin A2 & ANXA2 \\
\hline Annexin IV & ANXA4 \\
\hline Annexin V & ANXA5 \\
\hline$\beta$-1.4-Galactosyltransferase 4 & B4GALT4 \\
\hline$\beta$-2-Microglobulin precursor & B2M \\
\hline Bifunctional purine biosynthesis protein PURH & ATIC \\
\hline Biliverdin reductase A & BLVRA \\
\hline Bovine hemoglobin At Ph 5.7 & $\mathrm{BH}$ \\
\hline Calreticulin & CALR \\
\hline Cathepsin B precursor & CTSB \\
\hline Cofilin-1 & CFL1 \\
\hline Creatine kinase B-type & CKB \\
\hline Cytosolic nonspecific dipeptidase & CNDP2 \\
\hline Dipeptidyl peptidase 4 & DPP4 \\
\hline Endoplasmin precursor & HSP90B1 \\
\hline Eukaryotic initiation factor 4A-II & EIF4A2 \\
\hline Glutathione S-transferase M2 & GSTM2 \\
\hline Glutathione S-transferase Mu 1 & GSTM1 \\
\hline Glutathione S-transferase mu 3 & GSTM3 \\
\hline Glyceraldehyde-3-phosphate dehydrogenase & GAPDHS \\
\hline Glycogen phosphorylase, liver form & PYGL \\
\hline Heat shock cognate $71 \mathrm{kDa}$ protein & HSPA 8 \\
\hline Hemoglobin subunit $\beta$ & HBB \\
\hline Hemopexin precursor & HPX \\
\hline Ig gamma-2 chain $\mathrm{C}$ region & IGHG2 \\
\hline IgG2a heavy chain constant region & IGHG \\
\hline Inhibitor of carbonic anhydrase precursor & ICA \\
\hline Keratin, type II cytoskeletal 6A & KRT6 \\
\hline Leucine aminopeptidase protein & LAP3 \\
\hline Nucleobindin-2 precursor & NUCB2 \\
\hline Peroxiredoxin-1 & PRDX1 \\
\hline Peroxiredoxin- 4 precursor & PRDX4 \\
\hline Phosphatidylethanolamine binding protein from calf brain, chain A & PEB1 \\
\hline Phosphoglycerate mutase 1 & PGAM1 \\
\hline Plasma PAF acetylhydrolase & PAFAH \\
\hline PLC $\alpha$ & PLCA \\
\hline Protein disulfide-isomerase precursor & PDI \\
\hline Complement C1q tumor necrosis factor-related protein 5 & C1QTNF5 \\
\hline Purine nucleoside phosphorylase & $\mathrm{PNP}$ \\
\hline Pyruvate kinase isozymes M1/M2 & PKM \\
\hline Reticulocalbin-2 precursor & RCN2 \\
\hline Retinal dehydrogenase 1 & ALDH1A1 \\
\hline Ribonuclease 4 precursor & RNASE4 \\
\hline Seminal plasma protein A3-like & SFPA3L \\
\hline Serotransferrin precursor & $\mathrm{TF}$ \\
\hline Serpin A3-1 precursor & SERPINA3-1 \\
\hline Serpin A3-2 & SERPINA3-2 \\
\hline Serpin A3-2 precursor & SERPINA3-2 \\
\hline Spermadhesin Z13 precursor & SPHZ13 \\
\hline Stefin-C & STEFINC \\
\hline Transcobalamin-2 precursor & TCN2 \\
\hline Transketolase & TKT \\
\hline Transthyretin precursor & TTR \\
\hline Tubulin $\alpha-1 \mathrm{~B}$ chain & TUBA1B \\
\hline Tubulin $\alpha-\beta$ dimer, chain A & TUBA4A \\
\hline Vitamin D-binding protein precursor & $\mathrm{GC}$ \\
\hline WD repeat-containing protein 1 & WDR1 \\
\hline
\end{tabular}


Table 5. Proteins found only in bull seminal plasma

\begin{tabular}{|c|c|}
\hline Protein name & Short name \\
\hline Adenylate kinase isoenzyme 1 & AK1 \\
\hline$\alpha$-Centractin & $\mathrm{ACNT}$ \\
\hline$\alpha$-Mannosidase 2C1 & MAN2C1 \\
\hline Angiogenin 1 & ANG \\
\hline Aspartyl aminopeptidase & DNPEP \\
\hline Bovine lactoferrin & LTF \\
\hline cAMP-dependent protein kinase type I- $\alpha$ regulatory subunit & PRKAR1A \\
\hline Cystatin-M precursor & CST6 \\
\hline Dipeptidyl peptidase 2 precursor & DPP2 \\
\hline Double-headed protease inhibitor, submandibular gland-like & IPSG \\
\hline Epididymis-specific ERBP-like protein; ESP20.5-like & ERBPL \\
\hline Fructose-1,6-bisphosphatase 1 & FBP1 \\
\hline Functional ATP-dependent dihydroxyacetone kinase/FAD-AMP lyase (cyclizing) & DAK \\
\hline Galectin-3-binding protein precursor & LGALS3BP \\
\hline Glucose-6-phosphate isomerase & GPI \\
\hline Glucuronidase, $\beta$ & GUSB \\
\hline Glutathione peroxidase 3 precursor & GPX3 \\
\hline Heat shock $70 \mathrm{kDa}$ protein 1-like & HSPA1L \\
\hline Hemoglobin subunit $\alpha$ & HBA \\
\hline Hexokinase-1 & HK1 \\
\hline Hexosaminidase B & HEXB \\
\hline Nephronectin isoform 1 & NPNT \\
\hline Osteopontin, partial & SPP1 \\
\hline Phosphoglycerate mutase 2 & PGAM2 \\
\hline PRDX5 protein & PRDX5 \\
\hline Proactivator polypeptide & PSAPL1 \\
\hline Prostaglandin-H2 D-isomerase precursor PTGDS & PTGDS \\
\hline Proteasome subunit $\alpha$ type- 6 & PSMA6 \\
\hline Seminal plasma protein A3-like & SFPA3L \\
\hline Serotransferrin-like & LOC525947 \\
\hline Serpin peptidase inhibitor & SERPINB11 \\
\hline Sulfhydryl oxidase 1 precursor & QSOX1 \\
\hline T-complex protein 1 subunit $\alpha$ & CCT1 \\
\hline T-complex protein 1 subunit $\beta$ & CCT2 \\
\hline T-complex protein 1 subunit delta & CCT4 \\
\hline T-complex protein 1 subunit eta & CCT7 \\
\hline T-complex protein 1 subunit theta & CCT8 \\
\hline T-complex protein 1 subunit zeta & CCT6A \\
\hline Tripeptidyl peptidase I & TPP1 \\
\hline Tubulin $\beta-4 \mathrm{~B}$ chain & TUBB4B \\
\hline Tubulin polymerization-promoting protein family member 2 & TPPP2 \\
\hline Vacuolar $\mathrm{H}^{+}$-ATPase A subunit & ATP6V1A \\
\hline Vascular noninflammatory molecule 2 & VNN2 \\
\hline WAP 4-disulfide core domain protein 2 & WFDC2 \\
\hline
\end{tabular}

dismutase). This group was also characterized by the presence of tubulin isoforms (TUBA1B and TUBA4A). The presence of tubulin within this group indicates that those proteins are likely protected by chaperones (Sternlicht et al., 1993), which suggests that the protective action of chaperones is already exerted in seminal vesicle fluid. Some of the remaining proteins in this group, such as calreticulin, cofilin, or protein disulfide-isomerase precursor, are also connected to various aspects of mammalian spermatozoa functioning (Nakamura et al., 1993; Ellerman et al., 2006; Megnagi et al., 2015), but their relation with chaperones present in the described protein group is hard to establish at present. In our opinion, our results suggest that many proteins of seminal vesicles are protected by chaperones before ejaculation to guarantee their activity in seminal plasma where they interact with spermatozoa.

The second group distinguished in the seminal vesicle fluid proteome is involved in metabolic processes. It consists of 6 proteins involved in glycolysis, gluconeogenesis, and pentose phosphate pathways. Glycolysis is an important part of semen activity, involved in capacitation inhibition and providing a secondary energy source for spermatozoa (Storey, 2008). The presence of glycolytic and gluconeogenetic proteins in seminal vesicle fluid is most probably an indication of the metabolic processes taking place in seminal vesicles and its secretions.

The third group distinguished in the seminal vesicle fluid proteome was centered on albumin (ALB), and 
contained serotransferrin (TF) and clusterin (CLU). Those 3 proteins are well-known multifunctional proteins, connected with various aspects of homeostasis of seminal plasma and quality of semen (Kragh-Hansen, 1981; Ellison et al., 1988; Jones and Jomary, 2002; Elzanaty et al., 2007; Salehi et al., 2013). Albumin, TF, and CLU, along with the remaining proteins in this group, $\alpha$-1-antiproteinase, $\alpha$-2-HS-glycoprotein, and hemopexin, and 2 proteins connected to the group with lower confidence bonds, C-C motif chemokine 2 precursor and transthrein precursor, were involved in the liver $\mathrm{X}$ receptor/farnesoid $\mathrm{X}$ receptor $(\mathbf{L X R} / \mathbf{F X R})$ and farnesoid $\mathrm{X}$ receptor/retinoid X receptor (FXR/ RXR) activation canonical pathways. The LXR/FXR pathway takes part in lipid metabolism, inflammation, and cholesterol catabolism (Calkin and Tontonoz, 2012), and the FXR/RXR pathway is involved in lipid and glucose homeostasis, bile acid regulation, and inflammatory response (Ding et al., 2015). In summary, it seems that this protein group is characterized by the presence of multifunctional proteins, connected to the quality of semen, lipid metabolism, and inflammatory response.

Our results have shown that some seminal vesicle proteins identified in our study can differentiate between $\mathrm{X}$ and Y chromosome bearing bull spermatozoa, because these proteins already been identified by De Canio et al. (2014) as present in different abundance in $\mathrm{X}$ or $\mathrm{Y}$ bull spermatozoa. These proteins include binder of sperm protein (BSP) and glyceraldehyde-3-phosphate dehydrogenase (GAPDHS), previously recorded to be more abundant in X spermatozoa (De Canio et al., 2014). This suggests that proteins produced in seminal vesicles can differentially bind to $\mathrm{X}$ and $\mathrm{Y}$ spermatozoa, which is in accordance with work of de Graaf et al. (2008), who propositioned that seminal plasma proteins influence ram spermatozoa membranes and the sexing process of $\mathrm{X}$ and Y spermatozoa by flow cytom-

Table 6. Proteins found in both bull seminal veiscle fluid and bull seminal plasma

\begin{tabular}{|c|c|}
\hline Protein name & Short name \\
\hline 5'-Nucleotidase precursor & NT5E \\
\hline Actin, cytoplasmic 1 & ACTB \\
\hline Adenosylhomocysteinase & AHCY \\
\hline Aldose reductase & AKR1B1 \\
\hline$\alpha$-Enolase & ENO1 \\
\hline ART5 protein & ART5 \\
\hline Bovine Npc2 (Niemann-Pick C2) protein/epididymal secretory protein E1 & NPC2 \\
\hline Cathepsin A & CTSA \\
\hline Cathepsin D & CTSD \\
\hline Cathepsin L2 precursor & CTSL2 \\
\hline Cathepsin S & CTSS \\
\hline C-C motif chemokine 2 precursor & CCL2 \\
\hline Clusterin preproprotein & CLU \\
\hline Complement $\mathrm{C} 1 \mathrm{q}$ tumor necrosis factor-related protein 5 precursor & C1QTNF5 \\
\hline Complement C3 preproprotein & $\mathrm{C} 3$ \\
\hline Complement factor B precursor & CFB \\
\hline Complement factor $\mathrm{H}$ precursor & $\mathrm{CFH}$ \\
\hline Deoxyribonuclease gamma precursor & DNASE1L3 \\
\hline Ephrin-A1 precursor & EFNA1 \\
\hline Ezrin & EZR \\
\hline Glia-derived nexin precursor/serpin peptidase inhibitor & SERPINE2 \\
\hline Glucosidase. $\alpha$; neutral $\mathrm{AB}$ isoform 1 & GANAB \\
\hline Heat shock protein HSP $90-\alpha$ & HSP90AA1 \\
\hline Inhibitor, acrosin & ACRI \\
\hline Metalloproteinase inhibitor 2 , chain $\mathrm{T}$ & TIMP2 \\
\hline Nerve growth factor, partial & NGF \\
\hline Nucleobindin-1 precursor & NUCB1 \\
\hline Peptidyl-prolyl cis-trans isomerase B precursor & PPIB \\
\hline Phosphoglycerate kinase 1 & PGK1 \\
\hline Plasma serine protease inhibitor precursor & SERPINA5 \\
\hline Platelet-activating factor acetylhydrolase precursor & PLA2G7 \\
\hline Renin receptor & ATP6AP2 \\
\hline Seminal fluid protein A3-bovine & SFPA3 \\
\hline Seminal plasma protein BSP-30 kDa precursor & BSP5 \\
\hline Seminal plasma protein PDC-109 precursor & BSP1 \\
\hline Seminal ribonuclease precursor & SRN \\
\hline Serum albumin precursor & ALB \\
\hline Spermadhesin Z13 & SPHZ13 \\
\hline Spermadhesin-1 precursor & SPHZ1 \\
\hline Superoxide dismutase $(\mathrm{Cu}-\mathrm{Zn})$ & SOD1 \\
\hline
\end{tabular}


etry. It has to be stressed, however, that BSP possesses membrane-binding properties, but such properties have not been described yet for GAPDHS. Further research on seminal vesicles and seminal plasma proteomes may unravel the mechanism for modification of $\mathrm{X}$ and $\mathrm{Y}$ spermatozoa proteins, and possibly allow for improving the sorting process and storage of sexed semen.

To better understand the functions of seminal plasma proteins, we decided to combine our data with previously published research (Figure 5B) and analyze it using IPA and STRING analysis. The discrepancies in the number of identified proteins observed in all 3 studies are most probably the result of differences in analytical methods and the capabilities of the equipment used. By adding the proteins identified by Kelly et al. (2006) and Rego et al. (2014), we managed to increase the number of analyzed proteins from 85 to 128 , producing the most complete data set to date. The STRING analysis allowed the selection of 5 major groups of interconnected proteins (Figure 6), allowing deeper insight into specific functions of seminal plasma.

The protein group with the largest number of connections contained t-complex proteins connected with 2 heat shock proteins, 2 tubulins, and $\alpha$-centractin. Similar to the largest protein group in seminal vesicles, the biological role of this group of proteins is clearly related to the protection of proteins, as both t-complex and heat shock proteins are molecular chaperones. Because we found tubulins in seminal vesicle secretions, we can assume that their presence in the seminal plasma is not only related to spermatozoa but is also supplied by the accessory sex gland secretions. As mentioned before, tubulins are recognized as targets of protective actions of chaperone molecules. The presence of tubulin in both seminal vesicle fluid and seminal plasma suggests that the protective action of chaperones starts in seminal vesicle secretions and carries over to the semen after ejaculation. It is interesting to note that the protein group is linked to 2 proteasomes, PSMA6 and PSMB4. Our results strongly suggest that protein protection (presumably proteins of spermatozoa and tissues of reproductive system) is an important biological role of seminal plasma, based on mechanisms related to the activity of t-complex, heat shock proteins, and proteasome activity.

Another 2 of the 5 protein groups we found in seminal plasma mirrored the functionality of protein groups we found in seminal vesicle fluid. The proteins from the first group are involved in glycolysis and gluconeogenesis, and its presence both in seminal vesicles and seminal plasma confirms the importance of those metabolic pathways in bull semen. The second group consisted of multifunctional proteins such as ALB, TF, and CLU, and demonstrates varied protective functions and in- volvement in cholesterol metabolism. This group seems to be positively correlated with the correct morphology and functionality of spermatozoa, as indicated for apolipoprotein A1, lactotransferrin, metalloproteinase inhibitor 1, and gelsolin (Akerlöf et al., 1991; Baumgart et al., 2002; Finkelstein et al., 2010).

Beta-galactosidase (GLB1) was in the center of the next distinguished protein group, composed of proteins of presumably epididymal origin-aldose reductase (AKR1B1), $\beta$-glucuronidase, $\beta$-hexosaminidase (HEXB), and hexokinase 1, which is also involved in the glycolytic enzyme group described above. The GLB1 is a hydrolytic enzyme located mainly in the epididymis, which is probably involved in sperm maturation and can be an indicator for the function of the epididymal cauda (Jauhiainen and Vanha-Perttula, 1986; Dacheux et al., 2003). The AKR1B1 is associated with bull epididymosomes and epididymal spermatozoa (Frenette et al., 2003). The presence of those proteins in seminal plasma possibly reflects sperm maturation in the epididymis. Interestingly, all proteins from this group with the exception of HEXB can be linked to fertility-related processes, indicating their possible role in the female reproductive tract during capacitation or gamete interaction (Johnson and Hunter, 1972; Nikolajczyk and O'Rand, 1992; Snell and White, 1996; Katoh et al., 2014).

Immunological protection is an important part of the mechanism involved in protection of spermatozoa within the male and female reproductive system (Dacheux et al., 2003; Rodríguez-Martínez et al., 2011). Complement system proteins identified in our study constituted the majority of last of the distinguished protein groups, consisting of complement factors $\mathrm{B}$ and $\mathrm{H}$, complement C3 preprotein, and annexin A1. According to Harris et al. (2006), complement system activation is involved in the "selection of the fittest" spermatozoa in the epididymis (Belleannée et al., 2011), and clearance of dead and dying sperm cells. Both processes require spermatozoa to have complement-regulating proteins on their membranes, which were discovered on the surface of bull spermatozoa by Byrne et al. (2012). As seminal plasma affects female reproductive tract immunological responses (Rodríguez-Martínez et al., 2011), it is possible that seminal plasma complement factor proteins are partially involved in this interaction.

To perform an additional analysis of biological functions of bull seminal plasma proteins, we used IPA software (Supplemental Table S7; https://doi.org/10.3168/ jds.2016-11866). The results of IPA analysis mostly supported analysis performed with STRING, indicating multiple proteins with various protective functions directed toward other proteins as well as spermatozoa. Most importantly, analysis confirmed the importance of 


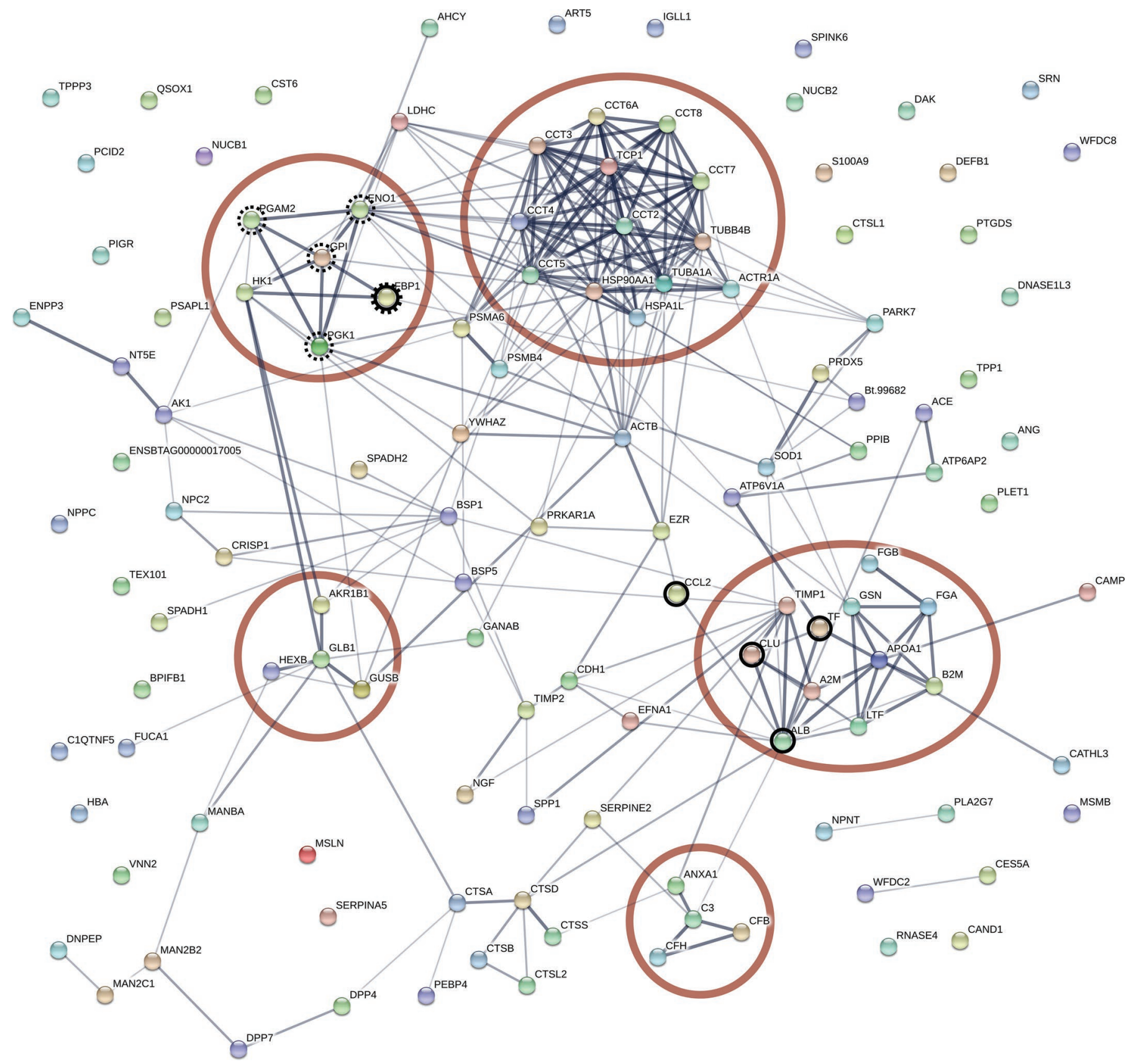

Figure 6. Search Tool for the Retrieval of Interacting Genes/Proteins (STRING) analysis of identified bull seminal plasma proteins, compiled using the data provided by our work, Kelly et al. (2006), and Rego et al. (2014). The proteins are connected with confidence network edges, the thicker the line, the greater the confidence of connection. Protein groups containing at least one protein connected to at least 4 other proteins with highest confidence bonds are circled; black lines mark proteins involved in liver X receptor/farnesoid X receptor (LXR/FXR) and farnesoid $\mathrm{X}$ receptor/retinoid X receptor (FXR/RXR) activation pathways; dotted black lines mark proteins involved in glycolysis and gluconeogenesis. Full protein names can be found in the UniProtKB database (www.uniprot.org). Color version available online.

t-complex proteins in seminal plasma. Functions shown by IPA for higher vertebrates strongly suggest that the t-complex is an important factor in spermatozoa motility, capacitation, and spermatozoa-oocyte interactions (Fraser and Dudley, 1999; Dun et al., 2011).
Contrary to our expectations, we could not identify all seminal vesicle fluid proteins in seminal plasma (Figure 5A). Additionally, seminal vesicle fluid showed abundance of some proteins, such as ALB and AKR1B1, to have dropped significantly, despite the fact that the 
abundance of the main proteins of both fluids (BSP1, BSP5, and spermadhesin) did not change significantly. The exact reason for those discrepancies is unknown at present. For some proteins, the lack of the detection in seminal plasma can simply be the result of the low detection limit caused by the dilution of seminal vesicle fluid. We believe that another reason is the adsorption of proteins on the spermatozoa. This suggestion is supported by the results of Byrne et al. (2012), which show the presence of several seminal vesicle fluid proteins unidentified in seminal plasma in our study on the surface of bull spermatozoa and also demonstrated the adsorption of albumin on spermatozoa, which coincides with our data indicating the loss of albumin in seminal plasma.

In summary, the bull seminal vesicle fluid proteome was described for the first time. Analysis of the seminal vesicle proteome suggests that some proteins were adsorbed on the surface of the spermatozoa. Our study has significantly expanded previously available data on bull seminal plasma by both increasing the number of proteins known, as well as providing a more detailed proteomic map. Both in seminal vesicle fluid and seminal plasma, we have indicated multiple protein networks that were involved in protective functions, glycolysis and gluconeogenesis, and lipid metabolism. Our results strongly suggest that protein protection is an important biological role of seminal plasma, based on mechanisms related to the activity of molecular chaperones. Further studies of both bull seminal plasma and seminal vesicle fluid should focus on detailed characteristics of the identified protein groups, to better understand the molecular background of sperm functioning, and to unravel the complex interactions between proteins.

\section{ACKNOWLEDGMENTS}

This work was supported by grants 2013/09/N/ NZ9/01655 and 2013/09/B/NZ9/01752 from the National Science Center and funds appropriated to Institute of Animal Reproduction and Food Research. We thank the personell of Breeding and Insemination Station in Karczew for providing the bull ejaculates and seminal vesicle fluid.

\section{REFERENCES}

Akerlöf, E., H. Jörnvall, H. Slotte, and A. Pousette. 1991. Identification of apolipoprotein A1 and immunoglobulin as components of a serum complex that mediates activation of human sperm motility. Biochemistry 30:8986-8990.

Baumgart, E., S. V. Lenk, S. A. Loening, and K. Jung. 2002. Tissue inhibitors of metalloproteinases 1 and 2 in human seminal plasma and their association with spermatozoa. Int. J. Androl. 25:369-371.
Belleannée, C., V. Labas, A. P. Teixeira-Gomes, J. L. Gatti, J. L. Dacheux, and F. Dacheux. 2011. Identification of luminal and secreted proteins in bull epididymis. J. Proteomics 74:59-78.

Byrne, K., T. Leahy, R. McCulloch, M. L. Colgrave, and M. K. Holland. 2012. Comprehensive mapping of the bull sperm surface proteome. Proteomics 12:3559-3579.

Calkin, A. C., and P. Tontonoz. 2012. Transcriptional integration of metabolism by the nuclear sterol-activated receptors LXR and FXR. Nat. Rev. Mol. Cell Biol. 13:213-224.

Cancel, A. M., D. A. Chapman, and G. J. Killian. 1999. Osteopontin localization in the holestein bull reproductive tract. Biol. Reprod. 60:454-460.

Dacheux, J. L., J. L. Gatti, and F. Dacheux. 2003. Contribution of epididymal secretory proteins for spermatozoa maturation. Microsc. Res. Tech. 61:7-17.

De Canio, M., A. Soggiu, C. Piras, L. Bonizzi, A. Galli, A. Urbani, and P. Roncada. 2014. Differential protein profile in sexed bovine semen: Shotgun proteomics investigation. Mol. Biosyst. 10:12641271.

de Graaf, S. P.. T. Leahy, J. Marti, G. Evans, and W. M. C. Maxwell. 2008. Application of seminal plasma in sex-sorting and sperm cryopreservation. Theriogenology 70:1360-1363.

Desnoyers, L., and P. Manjunath. 1992. Major proteins of bovine seminal plasma exhibit novel interactions with phospholipids. J. Biol. Chem. 267:10149-10155.

Ding, L., L. Yang, Z. Wang, and W. Huang. 2015. Bile acid nuclear receptor FXR and digestive system diseases. Acta Pharm. Sin. B $5: 135-144$.

Dun, M. D., N. D. Smith, M. A. Baker, M. Lin, R. J. A. Aitken, and B. Nixon. 2011. The chaperonin containing TCP1 complex (CCT/ $\mathrm{TRiC}$ ) is involved in mediating sperm-oocyte interaction. J. Biol. Chem. 286:36875-36887.

Ellerman, D. A., D. G. Myles, and P. Primakoff. 2006. A role for sperm surface protein disulfide isomerase acivity in gamete fusion: Evidence for the participation of ERp57. Dev. Cell 10:831-837.

Ellison, R. T., III, T. J. Giehl, and F. M. LaForce. 1988. Damage of the outer membrane of enteric gram-negative bacteria by lactoferrin and transferrin. Infect. Immun. 56:2774-2781.

Elzanaty, S., J. Erenpreiss, and C. Becker. 2007. Seminal plasma albumin: Origin and relation to the male reproductive parameters. Andrologia 39:60-65.

Finkelstein, M., N. Etkovitz, and H. Breitbart. 2010. Role and regulation of sperm gelsolin prior to fertilization. J. Biol. Chem. 285:39702-39709.

Fraser, L. R., and K. Dudley. 1999. New insights into the t-complex and control of sperm function. BioEssays 21:304-312.

Frenette, G., C. Lessard, E. Madore, M. A. Fortier, and R. Sullivan. 2003. Aldose reductase and macrophage migration inhibitory factor are associated with epididymosomes and spermatozoa in the bovine epididymis. Biol. Reprod. 69:1586-1592.

Harris, C. L., M. Mizuno, and B. P. Morgan. 2006. Complement and complement regulators in the male reproductive system. Mol. Immunol. 43:57-67.

Huntley, R. P., T. Sawford, P. Mutowo-Muellenet, A. Shypitsyna, C. Bonilla, M. J. Martin, and C. O'Donovan. 2015. The GOA database: Gene Ontology annotation updates for 2015. Nucleic Acids Res. 43:D1057-D1063.

Jauhiainen, A., and T. Vanha-Perttula. 1986. B-galactosidase in the seminal plasma and reproductive organs of the bull. Int. J. Biochem. 18:719-724.

Johnson, W. L., and A. G. Hunter. 1972. Seminal antigens: Their alteration in the genital tract of female rabbits and during partial in vitro capacitation with beta amylase and beta glucurnidase. Biol. Reprod. 7:332-340.

Jones, S. E., and C. Jomary. 2002. Clusterin. Int. J. Biochem. Cell Biol. 34:427-431.

Juyena, N. S., and C. Stelletta. 2012. Seminal plasma: An essential attribute to spermatozoa. J. Androl. 33:536-551.

Katoh, Y., K. Takebayashi, A. Kikuchi, A. Iki, K. Kikuchi, M. Tamba, A. Kawashima, M. Matsuda, and N. Okamura. 2014. Porcine 
sperm capacitation involves tyrosine phosphorylation and activation of aldose reductase. Reproduction 148:389-401.

Kelly, V. C., S. Kuy, D. J. Palmer, Z. Xu, S. R. Davis, and G. J. Cooper. 2006. Characterization of bovine seminal plasma by proteomics. Proteomics 6:5826-5833.

Kragh-Hansen, U. 1981. Molecular aspects of ligand binding to serum albumin. Pharmacol. Rev. 33:17-53.

Megnagi, B., M. Finkelstein, O. Shabtay, and H. Breitbart. 2015. The role and importance of cofilin in human sperm capacitation and the acrosome reaction. Cell Tissue Res. 362:665-675.

Moura, A. A., D. A. Chapman, H. Koc, and G. J. Killian. 2007. A comprehensive proteomic analysis of the accessory sex gland fluid from mature Holstein bulls. Anim. Reprod. Sci. 98:169-188.

Nakamura, M., M. Moriya, T. Baba, Y. Michikawa, T. Yamanobe, K. Arai, S. Okinaga, and T. Kobayashi. 1993. An endoplasmic reticulum protein, calreticulin, is transported into the acrosome of rat sperm. Exp. Cell Res. 205:101-110.

Nikolajczyk, B. S., and M. G. O'Rand. 1992. Characterization of rabit testis $\beta$-galactosidase and arylsulfatase A: Purification and localization in spermatozoa during the acrosome reaction. Biol. Reprod. 46:366-378.

Perkins, D. N., D. J. C. Pappin, D. M. Creasy, and J. S. Cottrell. 1999. Probability-based protein identification by searching sequence databases using mass spectrometry data. Electrophoresis 20:3551-3567.

Rego, J. P. A., J. M. Crisp, A. A. Moura, A. S. Nouwens, Y. Li, B. Venus, N. J. Corbet, D. H. Corbet, B. M. Burns, G. B. Boe-Hansen, and M. R. McGowan. 2014. Seminal plasma proteome of electroejaculated Bos indicus bulls. Anim. Reprod. Sci. 148:1-17.

Rickard, J. P., R. E. Schmidt, J. W. Maddison, R. Bathgate, G. W. Lynch, X. Druart, and S. P. de Graaf. 2016. Variation in seminal plasma alters the ability of ram spermatozoa to survive cryopreservation. Reprod. Fertil. Dev. 28:516-523.

Rodríguez-Martínez, H., U. Kvist, J. Ernerudh, L. Sanz, and J. J. Calvete. 2011. Seminal plasma proteins: What role do they play? Am. J. Reprod. Immunol. 66:11-22.

Salehi, M., H. Akbari, M. H. Heidari, A. Molouki, K. Murulitharn, H. Moeini, M. G. Novin, F. Aabed, H. Taheri, F. Fadaei, M. Mohsenzadeh, M. Jafari, A. Pirouzi, and R. Heidari. 2013. Correlation between human clusterin in seminal plasma with sperm protamine deficiency and DNA fragmentation. Mol. Reprod. Dev. 80:718-724.

Snell, W. J., and J. M. White. 1996. The molecules of mammalian fertilization. Cell 85:629-637.

Sternlicht, H., G. W. Farr, M. L. Sternlicht, J. K. Driscoll, K. Willison, and M. N. Yaffe. 1993. The t-complex polypeptide 1 complex is a chaperonin for tubulin and actin in vivo. Proc. Natl. Acad. Sci. USA 90:9422-9426.

Storey, B. T. 2008. Mammalian sperm metabolism: Oxygen and sugar, friend and foe. Int. J. Dev. Biol. 52:427-437.

Szklarczyk, D., A. Franceschini, S. Wyder, K. Forslund, D. Heller, J. Huerta-Cepas, M. Simonovic, A. Roth, A. Santos, K. P. Tsafou, M. Kuhn, P. Bork, L. J. Jensen, and C. von Mering. 2015. STRING v10: Protein-protein interaction networks, integrated over the tree of life. Nucleic Acids Res. 43:D447-D452. 